\title{
Análise ambiental de nascentes no perímetro urbano de Soledade (Rio Grande do Sul, Brasil)
}

Luiz Antônio Nicolodi Vivian', Marta Martins Barbosa Prestes², Marc Richter ${ }^{2,3}$, Erli Schneider Costa ${ }^{3}$, Daniela Mueller de Lara²

' Bacharel em Gestão Ambiental, egresso do Curso de Bacharelado em Gestão Ambiental, Universidade Estadual do Rio Grande do Sul (UERGS), Unidade Alto da Serra do Botucaraí, Soledade (RS).

2 UERGS. Unidade Alto da Serra do Botucaraí, Soledade (RS).

3 Programa de Pós-graduação em Ambiente e Sustentabilidade. UERGS. Unidade Hortênsias, São Francisco de Paula (RS). E-mails: luiz-vivian@uergs.edu.br, marta-barbosa@uergs.edu.br, marc-richter@uergs.edu.br, erli-costa@uergs.edu.br, daniela-lara@uergs.edu.br

\section{Resumo}

A degradação ambiental é um problema que se intensifica a cada ano sendo que um dos principais resultados é a redução de água potável disponível para consumo humano. A preservação das nascentes é de extrema importância para a recarga dos aquíferos e para garantia da quantidade e da qualidade da água disponível. Este trabalho teve como objetivo mapear e analisar a situação ambiental de nascentes no perímetro urbano de Soledade (Rio Grande do Sul, Brasil), por meio de imagens de satélites, sistemas de informações geográficas, e visitação in loco para a realização do diagnóstico ambiental. Utilizou-se como metodologia a pesquisa bibliográfica e a pesquisa-ação. Para o mapeamento das nascentes foram usados o Sistema de Informações Geográficas (SIGs) e o software de geoprocessamento ArcGis. Todas as nascentes foram visitadas e a análise ambiental levou em consideração os critérios: tipo de nascente, grau de conservação, proximidade com residências, acesso antrópico, presença de animais domésticos e de resíduos sólidos. Foram identificadas 3 I nascentes, sendo 18 classificadas como degradadas, 10 como perturbadas, duas (2) estavam canalizadas e apenas uma (I) preservada. A ausência de vegetação, o depósito irregular de resíduos sólidos, o cultivo de espécies exóticas (eucalipto), a proximidade de residências, o uso das nascentes para dessedentação animal, a proximidade de lavouras e de rodovias, o aterramento e a canalização de nascentes para loteamento foram os principais fatores de impacto as Áreas de Preservação Permanente (APP) das nascentes. Vale lembrar que a água é considerada pela ONU como um dos pontos prioritários para garantir o desenvolvimento sustentável, sendo o suprimento potável e a quantidade adequada de água um recurso chave para a garantia do desenvolvimento social e econômico. Sendo assim este estudo recomenda que a municipalidade de Soledade invista em ações de educação ambiental e capacitação dos gestores; priorize a definição de políticas públicas que promovam e incentivem a preservação das áreas de nascentes e, ao mesmo tempo adote medidas para recuperação das APPs. Recomenda-se ainda que os dados aqui apresentados sejam como subsídios para o planejamento da expansão urbana por meio da definição de áreas passíveis de ocupação e delimitação das áreas de preservação ambiental. Além de uma economia gerada a médio e longo prazo ao garantir água potável com menor necessidade de tratamento o município estaria contribuindo com a Agenda 2030 para o Desenvolvimento Sustentável e se posicionando a frente de outras municipalidades que ainda não realizam ações voltadas para este objetivo.

Palavras-chave: Gestão de recursos hídricos. Agenda 2030. Desenvolvimento Sustentável. Políticas públicas ambientais. Preservação ambiental.

\section{Abstract}

\section{Environmental analysis of freshwater springs in the soledade's urban area (Rio Grande do Sul, Brazil)}

Environmental degradation is intensifying every year, and one of the main results is the reduction of water available for human consumption. The spring's preservation is essential for the recharge of aquifers, and to ensure the 
quantity and quality of water available. This study aimed to map and analyze the environmental situation of springs in the urban area of Soledade (Rio Grande do Sul, Brazil), using satellite images, geographic information systems, and field activity for environmental diagnosis. The methodology used was bibliographic research and action research. Mapping the springs was performed using Geographic Information System (GIS) and the GIS software ArcGIS. All springs were visited, and the environmental analysis considered the criteria: type of spring, degree of conservation, proximity to homes, anthropic access, presence of farm animals, and waste deposit. Were identified springs $3 \mathrm{I}$, 18 are classified as degraded, as disturbed 10, two (2) channeled, and only one (I) preserved. The absence of vegetation, the irregular deposit of solid waste, the cultivation of exotic species (eucalyptus), the proximity of residences, the use of springs for animal desedentation, the vicinity of crops and highways, the grounding and the channeling of springs to allotment were the main factors impact the Permanent Preservation Areas of springs. It is worth remembering that water is considered by the UN as one of the priority points to ensure sustainable development, with drinking supply and adequate water being a vital resource for providing social and economic development. Thus, this study recommends that the municipality of Soledade invest in environmental education and training of managers; prioritize the definition of public policies that promote and encourage the preservation of spring areas and, at the same time, adopt measures for the recovery of PPAs. It also recommended that the data presented here be as subsidies for the planning of urban expansion through the definition of areas subject to occupation and delimitation of the territories of environmental preservation. With this measure, the municipality would be contributing to the 2030 Agenda for Sustainable Development and positioning itself ahead of other cities that still do not perform actions aimed at this goal.

Key-words: Water resource management. 2030 Agenda. Sustainable Development. Environmental public policies. Environmental preservation.

\section{Introdução}

A degradação ambiental é um problema que se intensifica a cada ano sendo que um dos principais resultados é a redução de água potável disponível para consumo humano (ANA, 20I3). Segundo a Organização das Nações Unidas (UNITED NATIONS, 20I5) se nenhuma providência for tomada para preservar as fontes de água potável e mudar o padrão de consumo dois terços da população global poderá sofrer com escassez de água doce até 2025. O problema é tão sério que a ONU ao definir os 17 Objetivos do Desenvolvimento Sustentável (ODS) da Agenda 2030 elencou o ODS 6: "Assegurar a disponibilidade e gestão sustentável da água e saneamento para todas e todos" (UNITED NATIONS, 2015). A água é o único recurso que recebeu um objetivo específico na Agenda 2030 e há uma relação direta entre este tópico e os ODSs II - "Tornar as cidades e os assentamentos humanos inclusivos, seguros, resilientes e sustentáveis" e 13 - "Tomar medidas urgentes para combater a mudança do clima e seus impactos" (SØRUP et al. 2019). Sendo assim podemos perceber que a disponibilidade de água potável e saudável é indispensável tanto para o desenvolvimento humano quanto para o desenvolvimento econômico (EGAN; AGYEMANG, 2019; VAL et al. 2019).

Em relação ao Brasil a Lei Federal $n^{\circ} 12.727 / 2012$ (alterada pela Lei $n^{\circ} 12.727 / 2012$ ), demonstra incisivamente o compromisso soberano do país com a tutela das suas florestas e demais formas de vegetação nativa, bem como da biodiversidade, do solo, dos recursos hídricos e da integridade do sistema climático, para o bem das gerações atuais e futuras (BRASIL, 20I2a, 20I2b). Ainda em relação ao ponto de vista legal, a mesma Resolução dispõe sobre parâmetros, definições e limites de Áreas de Preservação Permanente (APPs) incluindo áreas ao redor de nascentes ou olhos d'água, ainda que intermitente com raio mínimo de 50 metros de forma a proteger a bacia hidrográfica contribuinte (BRASIL, 20I2a).

Diante de problemas ambientais complexos e desafiadores em relação à qualidade hídrica identificamos a necessidade de que as municipalidades possam ter acesso a informações importantes sobre o estado das suas bacias hidrográficas e, mais especificamente neste trabalho, das nascentes que estão em sua área urbana, como no caso de Soledade (Rio Grande do Sul). São quatro as bacias hídricas que em parte tem suas nascentes abrigadas no município: bacias dos rios Butiá, Espraiado, Fão e São Bento; e, contribuem não somente para o abastecimento do próprio município mas também de diversos municípios vizinhos e outras regiões do estado. Em consonância com as leis federais, a Lei Municipal n 2955/2005 dispõe sobre a Política do Meio Ambiente de Soledade, tendo disposto no capitulo II, Art. $3^{\circ}$, inciso IX, o compromisso com a recuperação e preservação das nascentes, arroios e matas ciliares (SOLEDADE, 2005). 
Considerando o acima exposto o trabalho teve como objetivo mapear e analisar a situação ambiental de nascentes no perímetro urbano de Soledade (Rio Grande do Sul), por meio de imagens de satélites, sistemas de informações geográficas, e visitação in loco para a realização do diagnóstico ambiental. A equipe de trabaIho pretende assim fornecer dados importantes para subsidiar as autoridades municipais para a tomada de decisão adequada no que se refere a preservação do recurso hídrico da municipalidade.

\section{Materiais e Métodos}

Este trabalho foi desenvolvido no período de agosto de 2017 a novembro de 20I8, utilizando a metodologia de pesquisa-ação que, segundo Thiollent (1997), descreve uma situação problema com base em verbalizações dos diferentes autores em suas linguagens próprias, sendo o conhecimento das inferências inserido na elaboração de estratégias ou ações para desenvolvimento do trabalho. As fases de execução do projeto estão apresentadas na Figura I.

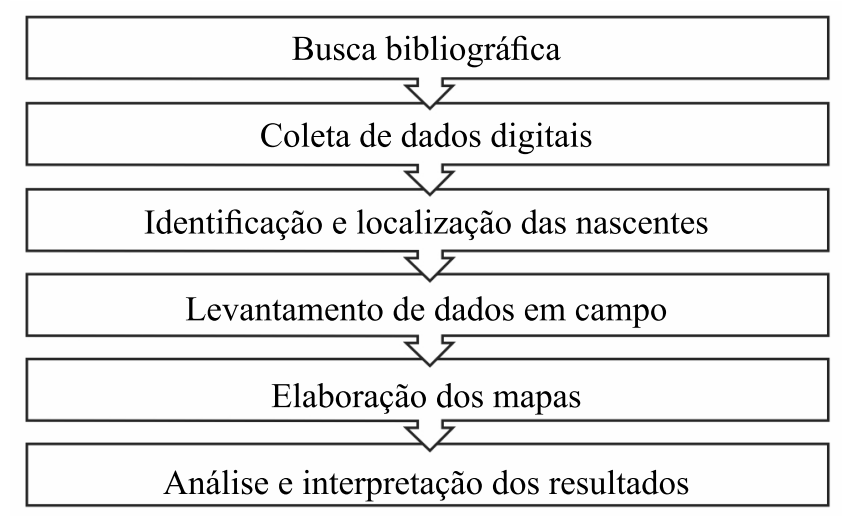

\section{Figura I}

Fluxograma das etapas de execução do trabalho baseado no método Pesquisa-Ação.

Fonte: Autores (2018).

Para a coleta de dados, foram realizados downloads dos arquivos shapefile dos limites dos municípios do Rio Grande do Sul (IBGE, 20I5), e dos arquivos shapefile dos recursos hídricos do Estado do Rio Grande do Sul (UFRGS, 20I3). As imagens foram baixadas do Google Earth Pro. Estes dados, posteriormente foram importados para o banco de dados do software de geoprocessamento ArcGis. Neste software (aplicativo ArcMap), foram delimitadas as áreas das quatro (4) bacias hidrográficas que do perímetro urbano de Soledade: as bacias dos rios Butiá, Espraiado, Fão e São Bento, gerando um novo shapefile com a delimitação destas. Foi delimitado também, utilizando-se polígonos, o perímetro urbano do município, usando a imagem do Google Earth Pro, e criando um novo shapefile, posteriormente utilizado para identificação das nascentes.

Foi considerada nascente cada início dos tributários dos Rios já mencionados, que compõem a rede de drenagem, os mesmos foram inseridos no shapefile de recursos hídricos. A visitação in loco permitiu realizar o mapeamento de cada nascente do perímetro urbano, sendo cada uma delas identificada pela letra $\mathrm{N}$ seguida de um numeral ( $\mid$ a $3 \mid$ ). Posteriormente, utilizando o software ArcGis, criou-se um novo shapefile com a localização das nascentes para identificar as áreas indicadas à municipalidade para preservação.

Em campo, foi realizado o registro fotográfico, e outros dados foram lançados em planilha (localização em coordenadas geográficas, tipo de nascente, grau de conservação da vegetação em torno das nascentes, proximidades com residências, acesso ao local, presença de animais, presença de resíduos sólidos). As coordenadas geográficas das nascentes foram registrados por meio do aplicativo My GPS Coordinates, software de localização. As nascentes foram classificadas de acordo o tipo de reservatório a que estão associadas, sendo diferenciadas em "pontuais", quando tem fluxo d'água em um único ponto do terreno ou "difusas" - possuem fluxos d'água em vários pontos do terreno - várias pequenas nascentes (LINSLEY; FRANZINI, 1978).

Para a avaliação do grau de conservação das nascentes, a vegetação em no entorno da considerada Área de Preservação Permanente (APP) foi medida com trena considerando raio mínimo de 50 metros conforme Resolução no 303 do CONAMA (BRASIL, 2002), sendo considerada como (RI) a vegetação acima da nascente, (R2) a vegetação abaixo seguindo o sentido de escoamento da água, (R3) à direita e (R4) à esquerda conforme exposto na Figura 2. 


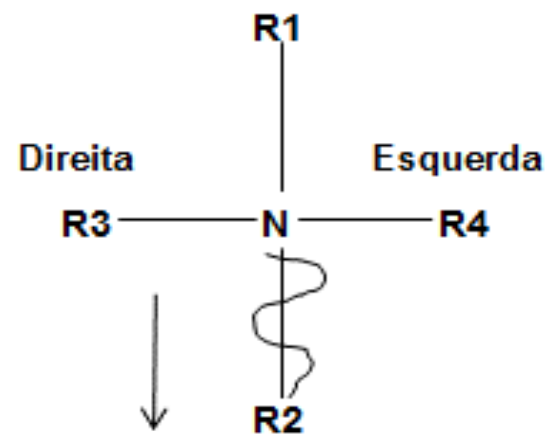

Figura 2

Sentido de medição da vegetação no entorno das nascentes considerando a Área de Preservação Permanente conforme .

\section{Sentido da água}

Fonte: Adaptado de Pinto (2003).

As nascentes também foram classificadas em três categorias conforme apresentado por Pinto (2003), sendo elas:

- Preservadas: Com pelo menos 50 metros de vegetação natural em seu entorno, e sem sinais de perturbação e degradação

- Perturbadas: Quando não apresenta 50 metros de vegetação em seu entorno mas apresentava bom estado de conservação, mesmo que com evidências de pastagem e agricultura.

- Degradadas: Com vegetação escassa ou ausente, com elevado grau de perturbação como com presença de residências, animais domésticos, solo compactado e resíduos sólidos.

Para elaboração de mapas e levantamento dos dados, utilizou-se o software de geoprocessamento ArcGis, que possui diversos recursos de layout e impressão, permite adicionar elementos, etiquetas de texto, imagens, barras de escala, formas básicas, legendas, cálculos de áreas, e ajustar as propriedades para criar o layout.

\section{Resultados e Discussão}

O município de Soledade está situado no Alto da Serra do Botucaraí, região norte do Rio Grande do Sul (Brasil) conforme apresentado na Figura 3, e possui cerca de 30.000 habitantes (IBGE, 20I0).
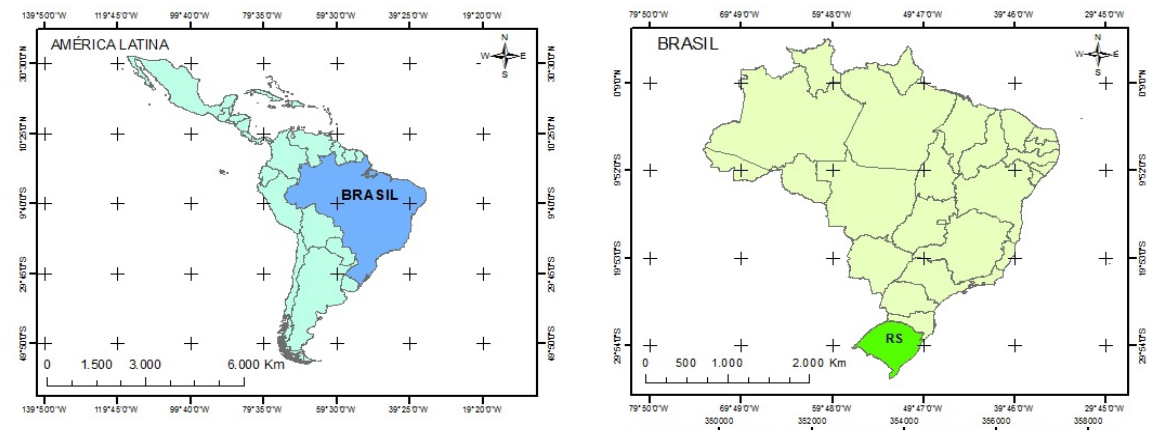

Figura 3

Mapa de localização do Município de Soledade no Rio Grande do Sul, Brasil. A linha vermelha indica o
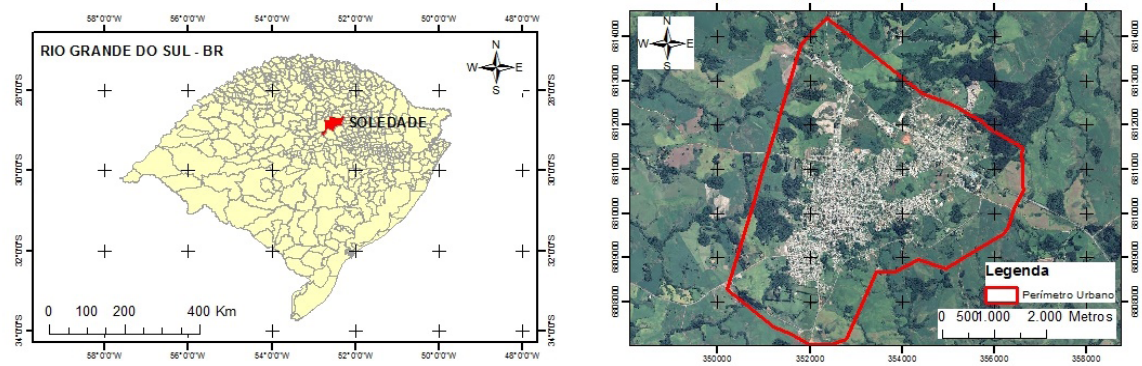
perímetro urbano do município, área de estudo deste trabalho.

Fonte: Nicolodi (2018).

O perímetro urbano de Soledade (RS) abrange parte dos recursos hídricos das bacias dos rios Butiá (linha verde), Espraiado (azul claro), Fão (azul escuro), e São Bento (marrom). É notória a contribuição hídrica das sub-bacias para o desenvolvimento econômico regional, para o estímulo à economia e para a promoção de alternativas adequadas para o desenvolvimento do município, assim como a grande responsabilidade na manutenção e preservação deste recurso tão precioso para a cidade. 


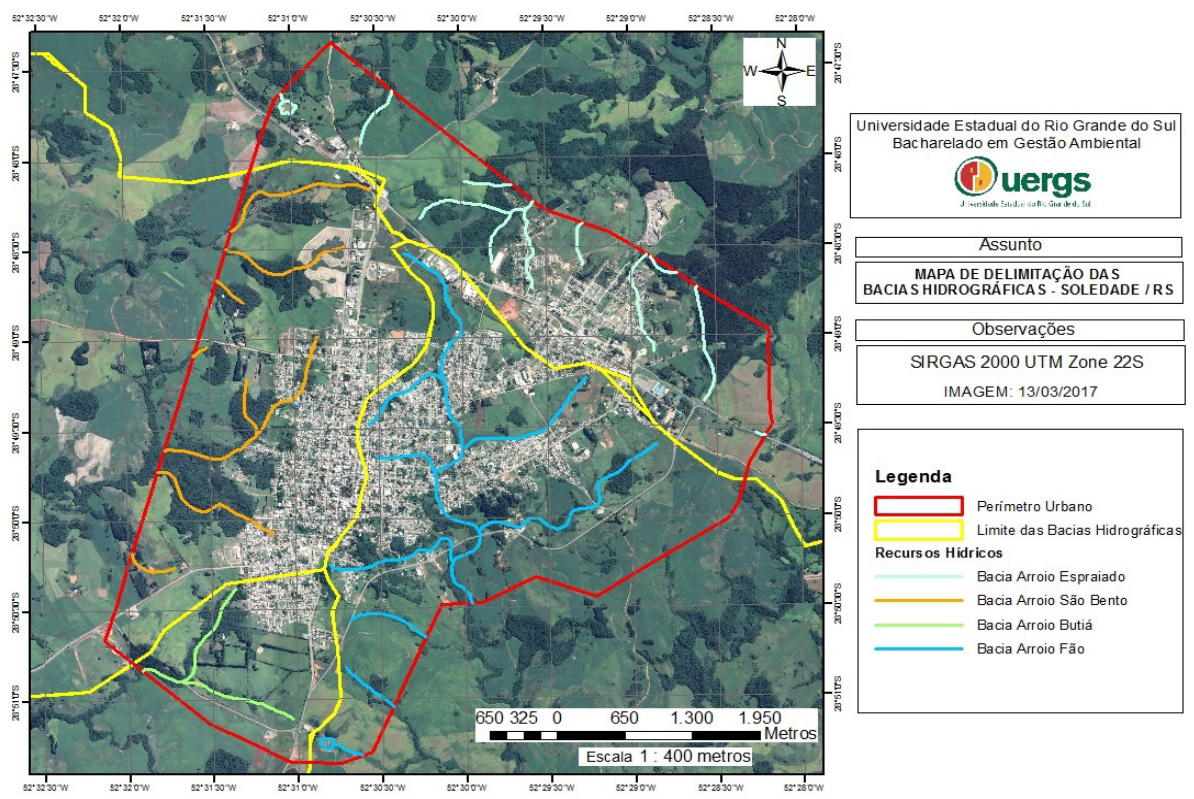

Figura 4

Delimitação do perímetro urbano e dos principais recursos hídricos do município de Soledade, Rio Grande do Sul, Brasil. As bacias estão representadas por cores: rio Butiá (linha verde), rio Espraiado (azul claro), rio Fão (azul escuro) e rio São Bento (marrom).

Fonte: Nicolodi (20I8).

A Figura 5 apresenta as nascentes localizadas no perímetro urbano de Soledade. A visita a campo foi de extrema importância para comprovar a existência de cada nascente, confrontando os dados obtidos por georreferenciamento. As atividades no local permitiram ainda avaliar a situação ambiental de cada nascente, garantindo maior confiabilidade nos dados.
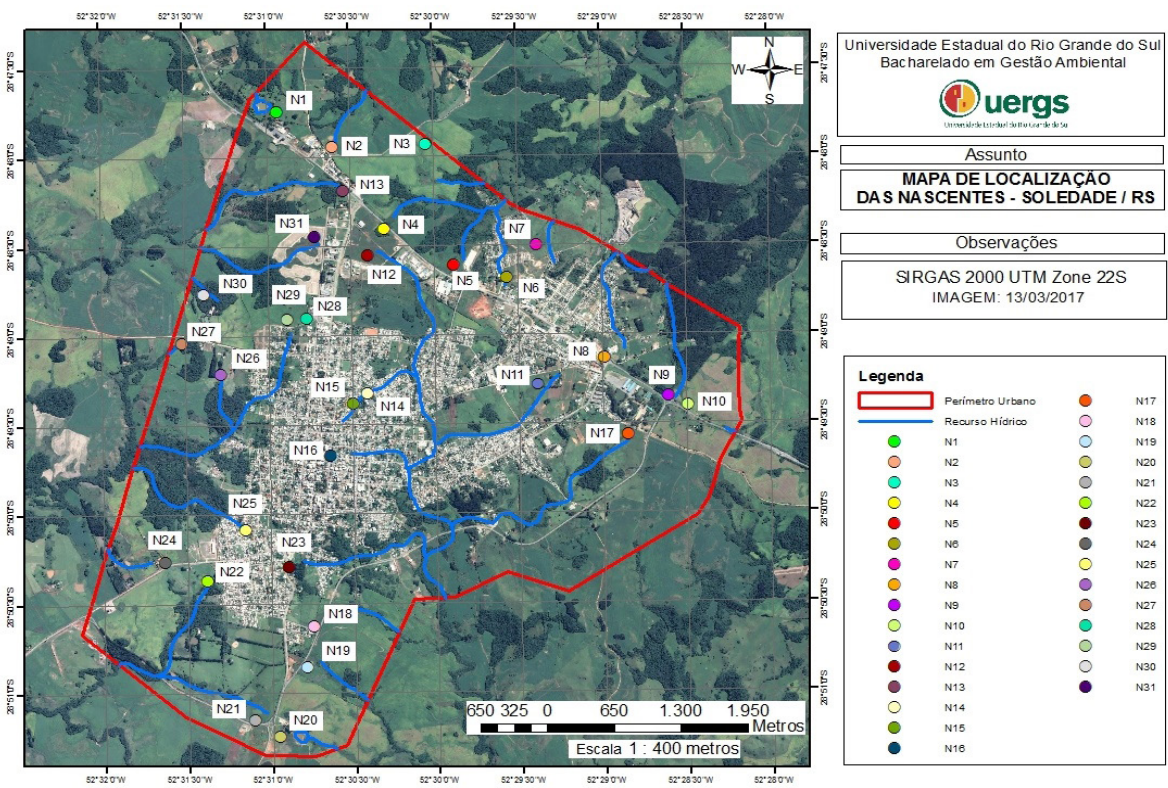

Figura 5

Localização das nascentes no perímetro urbano de Soledade, Rio Grande do Sul, Brasil.

Fonte: Nicolodi (20I8).

Foram identificadas $3 \mathrm{I}$ nascentes no perímetro urbano de Soledade (RS), sendo I 3 no bairro Botucaraí, uma (I) no Centro, uma (I) no Expedicionário, três (3) no Farroupilha, sete (7) no bairro Fontes, 4 no bairro Ipiranga e 2 no bairro Missões. Observando-se os dados obtidos percebe-se um deslocamento em relação a posição do recurso hídrico e os dados plotados no mapa. Entende-se que estas diferenças de devam ao uso de um GPS não geodésico, todavia como a proposta do trabalho não era obter dados exatos mas sim verificar a existência das nascentes consideramos os dados adequados para a apresentação neste momento. Caso exista a possibilidade e recursos disponíveis futuramente pode-se utilizar um GPS RTK Geodésico para aprimorar os dados obtidos. Adicionalmente como foram obtidas as posições exatas das nascentes por meio de visitas em campo houve a confirmação da existência das mesmas e isso poderá possibilitar nova localização e monitoramento no que se refere a adoção de medidas de proteção e preservação ambiental para o poder público e para a comunidade. 
Outros fatores podem influenciar na obtenção e na qualidade dos dados. Segundo Novo (2010), a interferência na qualidade final de dados obtidos da superfície, através de sistemas orbitais, possui influência na resposta espectral do objeto. $O$ autor complementa que os níveis de aquisição de dados determinam diferenças nas formas de análise, e consequentemente, nas informações obtidas. Para Barbosa (2005), fatores como nebulosidade, horário do dia, velocidade e direção do vento, podem provocar distorções nos sinais e imagens registradas. Já Crósta (1992) descreve em seu estudo, que imagens geradas por sensores remotos estão sujeitas a uma série de distorções espaciais, sendo necessário muitas vezes à integração com outros tipos de informação. A extração de informações através de Sensoriamento Remoto varia de acordo com nível de aquisição de dados, sendo que geralmente são realizadas coletas de informações em campo, como suporte para os dados obtidos (NOVO, 2010). Também é importante destacar que a perturbação exercida sobre as nascentes contribui para o deslocamento do recurso no terreno, ampliando as diferenças de localização.

Observou-se que das $3 \mathrm{I}$ nascentes encontradas, oito (8) foram classificadas como pontuais (26\%), 2 I como difusas (68\%) e duas (2) estão canalizadas (6\%). Entre as nascentes pontuais destacamos que N20 é utilizada para captação de água para consumo humano e não possui nenhum tipo de tratamento que anteceda o consumo. Das 31 nascentes localizadas no perímetro urbano, 18 nascentes encontravam-se degradadas $(58 \%), 10$ nascentes perturbadas (32\%), duas (2) nascentes (6\%) canalizadas e apenas uma (I) nascente (3\%) encontrava-se preservada.

Em relação à proximidade com residências observou-se que $65 \%$ das 31 nascentes estão localizadas próximas de residências, com distâncias de até 100 m e $26 \%$ apresentam residências a distâncias superiores a $100 \mathrm{~m}$, todavia isso também indica influência antrópica. Somente uma (I) nascente não tem residências nas suas proximidades e outras duas (2) estão canalizadas. Estas duas nascentes encontram-se nos bairros Centro (NI6) e Fontes (N25) e os locais caracterizam-se pela presença de entulhos, rejeitos, edificações e ainda indícios de terraplenagem sobre a área da nascente, possivelmente um preparo para construção de novas edificações. Analisando a possibilidade de acesso facilitado de humanos às nascentes registrou-se que $97 \%$ das nascentes são de fácil acesso sendo que somente a N27 que está localizada em uma área distante de residências, no interior de vegetação nativa pode ser considerada de difícil acesso. Essa nascente encontra-se relativamente preservada e sem evidências de ação antrópica.

Com respeito a presença de animais domésticos somente três nascentes podem ser consideradas "livres" de acesso sendo uma delas é canalizada. As outras 28 são frequentemente utilizadas para dessedentação de animais ou ainda estão muito próximas de áreas de criação como chiqueiros ou estábulos que contaminam a água de superfície e até mesmo o lençol freático (CALHEIROS et al., 2009). É uma situação preocupante pois tanto a população humana quanto a população animal podem sofrer com esta contaminação.

Já no que se refere ao depósito de resíduos sólidos próximos das nascentes a situação não é menos preocupante. Foi registrada a presença de resíduos sólidos em $61 \%$ das nascentes estudadas e em $39 \%$ somente não foram identificados pontos de depósito de resíduos sólidos. De acordo com Paraguassú et al. (20l0), a presença de resíduos sólidos próximo das nascentes está relacionado à facilidade de acesso, alteração na vegetação, proximidade com residências, assim como a falta de conscientização da população, o que leva a poluição nos sistemas hídricos.

Foram classificadas como degradadas 18 nascentes. Estas não apresentavam nenhum tipo de vegetação em seu entorno, alto grau de perturbação, sendo identificada a presença de residências, circulação de animais, solo compactado e resíduos sólidos. Quatorze nascentes (NI, N6, N7, N8, NI0, NII, NI2, $\mathrm{N} 13, \mathrm{~N} 15, \mathrm{~N} 21, \mathrm{~N} 22, \mathrm{~N} 28, \mathrm{~N} 29, \mathrm{~N} 31$ ) foram classificadas como difusas e quatro (N2, NI7, N24, N26) como pontuais. Os principais problemas identificados nestas nascentes foram ausência de vegetação, aterramento, uso das nascentes para dessedentação de animais, falta de cercamento, construção de rodovias sobre a APP, a presença de lavouras, os acúmulos de resíduos sólidos, loteamentos na área de APP, as edificações sobre a APP e o cultivo de eucaliptos. Já as 10 nascentes classificadas como perturbadas apresentam estado de conservação relativamente bom sendo que as principais perturbações registradas foram pouca vegetação (considerando até $50 \mathrm{~m}$ ), lavouras junto a APP, rodovias próximas, presença de animais, cultivo de eucaliptos, a proximidade com residências e a presença de resíduos sólidos. Apenas uma nascente foi classificada como preservada (N30), no bairro Fontes, e apresentava bom estado de conservação e vegetação abundante considerando presença de vegetação em seu entorno em extensão 
superior a $50 \mathrm{~m}$. Esta nascente já foi usada para abastecer piscinas artificiais em um antigo camping que encontra-se desativado. Embora a piscina esteja próxima da nascente, como não é utilizada, permitiu que a vegetação natural se estabelecesse no entorno, contribuindo para a preservação da mesma.

Os dados apresentados neste trabalham reforçam a necessidade de que é urgente a adoção de medidas para preservação da nascente que ainda está classificada como preservada e, principalmente, a adoção de medidas de recuperação das nascentes já degradas. A água é extremamente necessária para a manutenção da vida de todos os seres vivos, sendo que a qualidade e quantidade deste recurso tão precioso está diretamente ligada a nossas atitudes e ações no que se refere a preservação ambiental. Neste contexto o diagnóstico aqui apresentado fornece dados importantes para o subsídio de um plano de ação para definir estratégias de planejamento urbano, bem como a gestão adequada para a conservação das nascentes e demais recursos hídricos.

\section{Considerações Finais}

O estudo realizado teve como objetivo mapear e analisar a situação ambiental das nascentes localizadas no perímetro urbano do município de Soledade (RS) como forma de gerar dados que auxiliem a municipalidade a realizar o planejamento urbano de forma mais efetiva colocando como prioridade a preservação das nascentes. $O$ registro de dados permite o monitoramento a médio e longo prazo uma vez que foi apresentada a classificação das nascentes em relação ao estado de preservação em que se encontram. Com base nos dados que obtivemos podemos afirmar que as maiores causas de degradação estão relacionadas à falta de vegetação nas Áreas de Preservação Permanente (APPs), o uso das nascentes para dessedentação animal (equinos e bovinos), presença de lavouras, o aterramento e a canalização das nascentes para loteamento e construção de moradias e outras obras.

Somente uma das nascentes apresenta a APP adequada em conformidade com o Código Florestal (Lei $n^{\circ} 12.65 \mathrm{I} / 2012$, alterada pela Lei $n^{\circ} 12.727 / 2012$ ) apresentando raio mínimo de 50 metros de área preservada em seu entorno (BRASIL, 20I2a, 20I2b). As demais nascentes apresentam graves problemas de preservação pois a falta de definição da área de preservação facilita a ação antrópica e a degradação dos ambientes próximos das nascentes colocando em risco em médio e longo prazo o abastecimento de água potável para o município e para a região. Desta forma recomenda-se as autoridades municipais que avaliem e adotem medidas de recuperação e fiscalização destes ambientes de forma a garantir a preservação; conforme a legislação federal e leis municipais 2955/2005 e 3027/2006; (SOLEDADE, 2005,2006 ), visto que os dados apresentados reforçam a necessidade de tomada de decisão e ação efetiva dos órgãos competentes. A fiscalização cuidadosa e frequente destes ambientes é uma medida importante para auxiliar no planejamento da expansão urbana garantindo a preservação dos recursos naturais. Ademais as ações de conscientização e educação ambiental da população vizinha às áreas de nascentes, incluindo proprietários de áreas nas quais as mesmas estão localizadas pode ser fundamental para uma mudança de comportamento e reconhecimento da importância das nascentes para garantir a disponibilidade de água potável a médio e longo prazo.

Vale lembrar que a água é considerada pela ONU como um dos pontos prioritários e que merece atenção da sociedade para garantir o desenvolvimento sustentável. O suprimento seguro e a quantidade adequada de água é um recurso chave para o desenvolvimento social e econômico segundo diversas organizações internacionais entre elas a Organização Mundial da Saúde (OMS), Organização das Nações Unidas para a Educação, Ciência e Cultura (UNESCO), Programa das Nações Unidas para o Meio Ambiente (PNUMA) e Organização das Nações Unidas para Agricultura e Alimentação (FAO) (VAL et al., 2019).

São recomendados para a municipalidade de Soledade como forma de garantir a proteção da qualidade de água na região um esforço em educação ambiental e capacitação dos gestores; a definição de políticas públicas claras que promovam e incentivem a preservação das áreas de nascentes e, ao mesmo tempo coleta e destinação adequada dos resíduos sólidos que contaminam as nascentes, recuperação do solo degradado e respeito da distância do raio de 50 metros para o uso do solo; esforço para recuperação da vegetação nas bacias hidrográficas e consequente reparação das matas ciliares; entre outras medidas. Pode parecer um plano oneroso todavia o tratamento para obtenção da água potável pode custar até $U \$ 90,00$ (noventa dólares) para cada $1000 \mathrm{~m}^{3}$, enquanto que o tratamento de água cristalina e não contaminada não custa mais do que U\$3,00 (três dólares) (TUNDISI; MATSUMURA-TUNDISI, 20I0). 
Além disso ainda devem ser consideradas e avaliadas as vantagens associadas à preservação como por exemplo, o potencial de recreação e o turismo; redução de internações devido a doenças causadas por água contaminada ou intoxicação e, por consequência, a redução de número de faltas ao trabalho; e no caso das crianças maior aproveitamento das atividades escolares no momento em que o número de faltas é reduzido (VAL et al., 2019). Levando em consideração o fator econômico a sensibilização dos gestores para a mudança de comportamento pode ser mais efetiva e garantir a preservação dos recursos hídricos para as futuras gerações, sem contar na economia gerada a médio e longo prazo. Adicionalmente o município estaria contribuindo claramente com a Agenda 2030 para o Desenvolvimento Sustentável e se posicionando a frente de outras municipalidades que ainda não realizam ações voltadas para este objetivo.

\section{Agradecimentos}

Este artigo é resultado do Trabalho de Conclusão de curso em Gestão Ambiental do primeiro autor (Unidade Alto da Serra do Botucaraí, Soledade). Para ter acesso ao trabalho completo pode ser realizada solicitação por e-mail. Os autores agradecem aos revisores anônimos pelas excelentes contribuições que aprimoraram a redação deste artigo.

\section{Referências}

ANA. Agência Nacional de Águas. O risco de escassez de água doce. 2013. Disponível em: https:/www.ana.gov.br/ noticias-antigas/o-risco-de-escassez-de-a-gua-doce.2019-03-15.4724785357. Acesso em: 27 nov. 2019.

BARBOSA, C. C. F. Sensoriamento Remoto da dinâmica de circulação da água do sistema planície de Curai/ Rio Amazonas. Tese de Doutorado (Curso de Pós-Graduação em Sensoriamento Remoto) - Instituto Nacional de Pesquisas Espaciais (INPE), São José dos Campos, SP: 2005.

BRASIL. Lei $\mathbf{n}^{\circ}$ 12.65 I de 25 de Maio de 2012. Estabelece normas gerais sobre a proteção da vegetação, áreas de preservação permanente, 2012 a. [...]. Disponível em: http://www.planalto.gov.br/ccivil_03/_ato201 I-2014/2012/lei/ II 265 I.htm. Acesso em: 27 nov. 2019.

BRASIL. Lei $\mathbf{n}^{\circ} \mathbf{1 2 . 7 2 7}$ de $\mathbf{1 7}$ de Outubro de 20|2. Estabelece normas gerais sobre a proteção da vegetação, áreas de preservação permanente, altera a lei $n^{\circ} 12.65 \mathrm{I}$ de 25 de maio de $2012 \mathrm{~b}$ [...]. Disponível em: http://www.planalto. gov.br/ccivil_03/_ato20I I-20I4/20I2/lei/LI2727.htm. Acesso em: 27 nov. 2019.

CALHEIROS, R. de O. et al. Secretaria de Estado do Meio Ambiente. Departamento de Proteção da Biodiversidade. Caderno da Mata Ciliar, n, I, São Paulo, SP, 2009. Disponível em: https://www.sigam.ambiente.sp.gov.br/sigam3/ Repositorio/222/Documentos/Cadernos_Mata_Ciliar_I_Preservacao_Nascentes.pdf. Acesso em: 27 nov. 2019.

CRÓSTA, A. P. Processamento digital de imagens de sensoriamento remoto. São Paulo: Ig/Unicamp, 1992.

EGAN, M.; AGYEMANG, G. Progress towards sustainable urban water management in Ghana. Sustainability Accounting, Management and Policy Journal, 10(2), 235-259, 2019. Disponível em: https://doi.org/10.1 I08/SAMPJ-09-2018-0232. Acesso em: 27 nov. 2019.

IBGE. INSTITUTO BRASILEIRO DE GEOGRAFIA E ESTATÍSTICA. Histórico dos municípios. Rio de Janeiro: IBGE, 20 I0. Disponível em: https://cidades.ibge.gov.br/brasil/rs/soledade/panorama. Acesso em: 3l jul. 2018.

Mapas, bases e referencias. Rio de Janeiro: IBGE, 2015. Disponível em: https://mapas.ibge.gov.br/bases-e-referenciais/bases-cartograficas/malhas-digitais. Acesso em: 01 jul. 2018.

LINSLEY, R. K.; FRANZINI, J.B. Engenharia de recursos hídricos. Porto Alegre: Grupo A; Mc Graw-Hill do Brasil, 1978.

NOVO, E. M. L. de M. Sensoriamento remoto: princípios e aplicações. 4. ed. São Paulo, SP: Blucher, 2010.

PARAGUASSÚ, L. et al. Influência da urbanização na qualidade das nascentes de parques municipais em Belo Horizonte (MG). Anais do VIII SIMPÓSIO NACIONAL DE GEOMORFOLOGIA, Recife (PE). 2010. Disponível em: http://lsie.unb. br/ugb/sinageo/8/l/6I.pdf. Acesso em: 27 jan. 2018.

PINTO, L. V. A. Estudo das nascentes e caracterização física da sub-bacia do Ribeirão Santa Cruz, Lavras, MG, utilizando geoprocessamento. 2003. Dissertação (Mestrado em Manejo Ambiental) - Curso de Mestrado em Engenharia Florestal, Universidade Federal de Lavras, Minas Gerais, 2003. 
SOLEDADE. Lei $\mathbf{n}^{\circ} \mathbf{2 9 5 5}$ de 22 de Julho de 2005. Dispõe sobre a política do meio ambiente do município de Soledade e dá outras providências. Disponível em: https://www.soledade.rs.gov.br/publicacoes/publicacao/lei29552005/3882. Acesso em: 27 nov. 2019.

SOLEDADE. Lei $\mathbf{n}^{\circ} \mathbf{3 . 0 2 7}$ de 03 de Outubro de 2006. Institui o plano diretor do município de Soledade. Disponível em: https://www.soledade.rs.gov.br/publicacoes/publicacao/lei-30272006/3954. Acesso em: 27 nov. 2019.

SØRUP, H. J. D.; ARNBJERG-NIELSEN, K.; FEILBERG, M.; LIU, L.; FRYD, O.; ULBAK, K. A.; JENSEN, M. B. Sustainable climate change adaptation of urban water management in compliance with the UN SDGs. Abstract from I0th edition of the NOVATECH CONFERENCE, Lyon, France, 2019.

THIOLLENT, M. Metodologia da Pesquisa-Ação. 6. ed. São Paulo, SP: Cortez, 1997.

TUNDISI, J.G.; MATSUMURA-TUNDISI, T. Impactos potenciais das alterações do Código Florestal nos recursos hídricos. Biota Neotropica, I0(4): 67-76, 2010.

UNITED NATIONS. "Transforming our World: The 2030 Agenda for Sustainable Development", 2015. Disponível em: https://sustainabledevelopment.un.org/post2015/transformingourworld. Acesso em: 27 de nov. de 2019.

UFRGS. UNIVERSIDADE FEDERAL DO RIO GRANDE DO SUL. Base cartográfica vetorial continua do Rio Grande do Sul. 2013. Disponível em: <shorturl.at/kCNO9>. Acesso em: 01 jul. 2018

VAL, A.L. et al. Water Quality in the Americas - Risks and Opportunities. In: Water Quality In Brazil México: Unesco; IANAS, 2019. P. 103-126. Disponível em: https://www.ianas.org/images/books/wb/0.pdf. Acesso em: 27 de nov. de 2019. 